УДК 532.614+546

\title{
Interaction of $\mathrm{Bi}_{2} \mathrm{O}_{3}-\mathrm{B}_{2} \mathrm{O}_{3}$ \\ Melts with Crucible Materials
}

\section{Liubov T. Denisova*, Dmitriy O. Krinitsyn, Nataliya V. Belousova and Galina M. Zeer* \\ Siberian Federal University \\ 79 Svobodny, Krasnoyarsk, 660041 Russia}

Received 09.10.2015, received in revised form 24.11.2015, accepted 03.12.2015

The wetting of crucible materials $(\mathrm{Ag}, \mathrm{Au}$, and $\mathrm{BeO})$ by $\mathrm{B}_{2} \mathrm{O}_{3}-\mathrm{Bi}_{2} \mathrm{O}_{3}$ melts with low content of second component was investigated by the method of sessile drop. The effect of temperature on the wetting of substrates by the $\mathrm{B}_{2} \mathrm{O}_{3}$-based melts was determined. The obtained values of molar work of adhesion point to physical interaction of the phases.

Keywords: wetting, wetting angle, silver, gold, oxides of bismuth, boron and beryllium.

DOI: $10.17516 / 1998-2836-2015-8-4-550-558$.

(C) Siberian Federal University. All rights reserved

* Corresponding author E-mail address: antluba@mail.ru 


\title{
Взаимодействие расплавов $\mathrm{B}_{2} \mathrm{O}_{3}-\mathrm{Bi}_{2} \mathrm{O}_{3}$ \\ с тигельными материалами
}

\author{
Л.Т. Денисова, Д.О. Криницин, \\ Н.В. Белоусова, Г.М. Зеер \\ Сибирский федеральный университет \\ Россия, 660041, Красноярск, пр. Свободный, 79
}

\begin{abstract}
Методом лежащей капли исследовано смачивание тигельных материалов (Ag, $\mathrm{Au}$ и ВеO) расплавами $\mathrm{B}_{2} \mathrm{O}_{3}-\mathrm{Bi}_{2} \mathrm{O}_{3}$ с низким содержанием второго компонента. Определено влияние температуры на смачивание расплавами на основе $B_{2} O_{3}$ твердых подложек. Полученные значения молярной работы адгезии для анализируемых систем указывают на физическое взаимодействие фаз.
\end{abstract}

Ключевые слова: смачивание, растекание, краевой угол, серебро, золото, оксиды бора, висмута и бериллия.

\section{Введение}

Бораты висмута в течение длительного времени привлекают внимание исследователей благодаря своим оптическим и физико-химическим свойствам [1-9]. Связано это с тем, что у них были обнаружены нелинейно-оптические свойства [10]. Это дает возможность использовать такие материалы в нелинейной оптике для создания твердотельных ультрафиолетовых лазеров [11].

Известно, что при получении кристаллов оксидных соединений на основе $\mathrm{Bi}_{2} \mathrm{O}_{3}$ происходит растворение в них платинового тигля [12]. Установлено, что материал тигля влияет на свойства получаемых оксидных соединений $[13,14]$. В то же время особенности взаимодействия расплавов $\mathrm{B}_{2} \mathrm{O}_{3}-\mathrm{Bi}_{2} \mathrm{O}_{3}$ с тигельными материалами исследованы недостаточно, хотя именно значение макроскопического краевого угла смачивания позволяет судить о применимости того или иного материала к решению ряда практических задач. Имеющиеся данные по смачиванию расплавами $\mathrm{B}_{2} \mathrm{O}_{3}-\mathrm{Bi}_{2} \mathrm{O}_{3}$ серебра [15], золота [16], платины [17] и иридия [18] относятся в основном к химическим соединениям системы $\mathrm{B}_{2} \mathrm{O}_{3}-\mathrm{Bi}_{2} \mathrm{O}_{3}$. Сведения о смачивании тигельных материалов расплавами $\mathrm{B}_{2} \mathrm{O}_{3}-\mathrm{Bi}_{2} \mathrm{O}_{3}$ с низким содержанием второго компонента в литературе отсутствуют.

Цель настоящей работы - исследование взаимодействия расплавов $\mathrm{B}_{2} \mathrm{O}_{3}-\mathrm{Bi}_{2} \mathrm{O}_{3}$ с твердыми $\mathrm{Ag}, \mathrm{Au}$ и $\mathrm{BeO}$.

\section{Результаты и их обсуждение}

Эксперименты по смачиванию твердых подложек расплавами $\mathrm{B}_{2} \mathrm{O}_{3}-\mathrm{Bi}_{2} \mathrm{O}_{3}$ вели на воздухе при раздельном нагреве образца и подложки методом лежащей капли. Методика экспериментов подобна описанной в работе [16]. Для приготовления образцов использовали $\mathrm{B}_{2} \mathrm{O}_{3}$ и $\mathrm{Bi}_{2} \mathrm{O}_{3}-$ ос.ч.

$$
-551-
$$


Проведенные опыты по смачиванию $\mathrm{Ag}, \mathrm{Au}$ и $\mathrm{BeO}$ жидким оксидом бора показали, что с течением времени $\tau$ контактные углы смачивания уменьшаются, а после некоторого значения $\tau$ они не изменяются. В качестве примера на рис. 1 показано смачивание $\mathrm{Au}$ и $\mathrm{BeO}$ расплавом $\mathrm{B}_{2} \mathrm{O}_{3}$. Можно видеть, что в течение достаточно малого времени происходит сильное изменение $\Theta$, а затем в течение длительного времени значения $\Theta$ мало изменяются. Такой характер изменения $\Theta$ с течением времени $\Theta=f(\tau)$ связывают [19] с вязкостным режимом. Аналогичным образом происходит взаимодействие жидкого $\mathrm{B}_{2} \mathrm{O}_{3}$ с серебром.

Принимая последние значения $\Theta$ за равновесные, исследовали влияние температуры на смачивание $\mathrm{BeO}, \mathrm{Ag}$ и $\mathrm{Au}$ жидким $\mathrm{B}_{2} \mathrm{O}_{3}$ (рис. 2).

Следует отметить, что, несмотря на более высокие значения квазиравновесных углов смачивания на положках из оксида бериллия и серебра при низких температурах, при $T>773 \mathrm{~K}$ угол смачивания, образуемый жидким оксидом бора, на подложке из золота практически не меняется, в то время как на других подложках значения $\Theta$ уменьшаются.
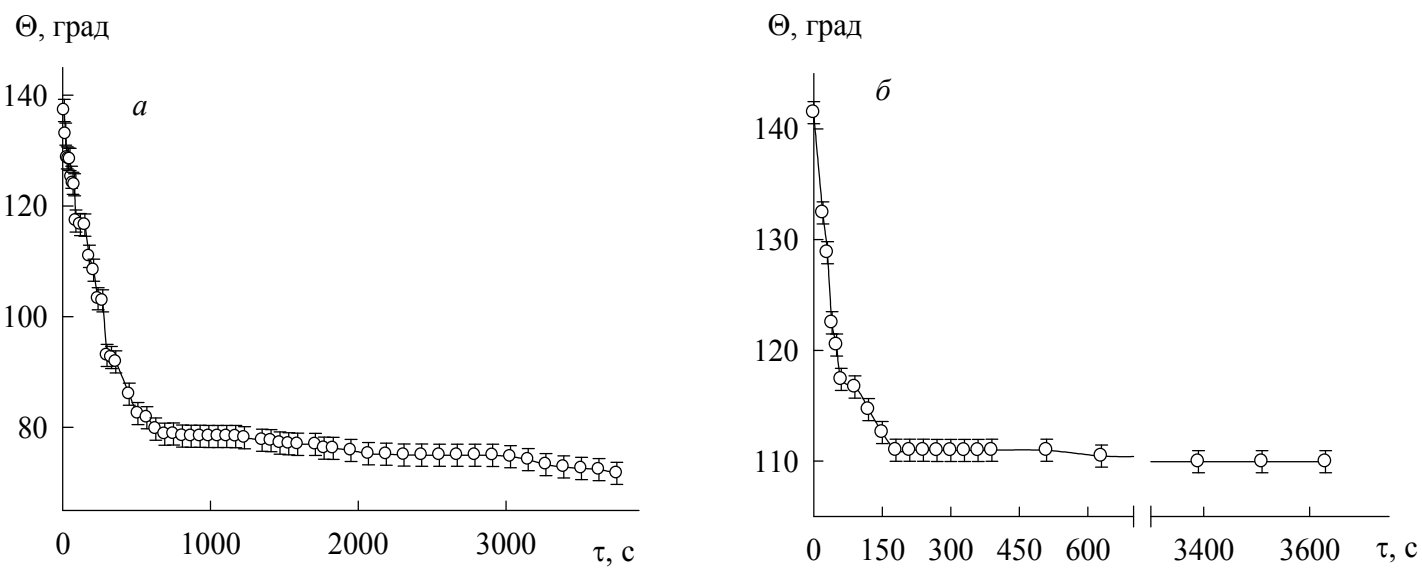

Рис. 1. Смачивание $\mathrm{Au}(a)$ и $\mathrm{BeO}(б)$ расплавом $\mathrm{B}_{2} \mathrm{O}_{3}$ при $753 \mathrm{~K}$

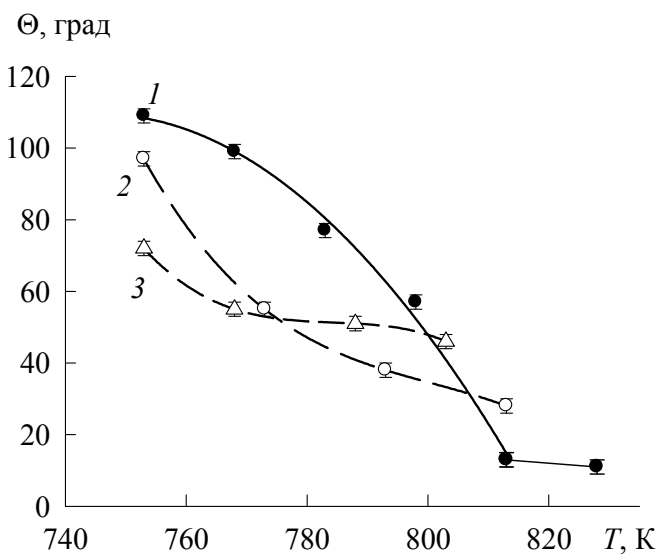

Рис. 2. Влияние температуры на смачивание расплавом $\mathrm{B}_{2} \mathrm{O}_{3}$ твердых $\mathrm{BeO}(1), \mathrm{Ag}(2)$ и $\mathrm{Au}(3)$ 
Кинетика растекания расплава $\mathrm{B}_{2} \mathrm{O}_{3}+1$ мол. \% $\mathrm{Bi}_{2} \mathrm{O}_{3}$ по подложкам из $\mathrm{Ag}$ и $\mathrm{Au}$ показана на рис. 3 и 4.

Из этих данных следует, что характер растекания такого расплава по Ag и Аu одинаков, т.е. наблюдается быстрое изменение начальных краевых углов смачивания при температуре перехода твердых висмутборатных оксидов в жидкое состояние, а затем наблюдается длительное растекание, после которого значения $\Theta$ не изменяются.

Это позволило исследовать влияние температуры на смачивание $\mathrm{Ag}$ и $\mathrm{Au}$ расплавами $\mathrm{B}_{2} \mathrm{O}_{3}$ +1 мол. \% $\mathrm{Bi}_{2} \mathrm{O}_{3}$. Эти результаты приведены на рис. 5. Видно, что на подложке из золота значения $\Theta$ выше 950 K практически не изменяются, тогда как на $\mathrm{Ag}$ краевые углы смачивания этим расплавом уменьшаются во всем исследованном интервале температур.

Наличие данных $\Theta=f(T)$ и сведений о температурной зависимости поверхностного натяжения расплавов $\mathrm{B}_{2} \mathrm{O}_{3}-\mathrm{Bi}_{2} \mathrm{O}_{3}$ [20] позволило по уравнению Юнга-Дюпре [19]

$$
W_{a}=\sigma(1+\cos \Theta)
$$
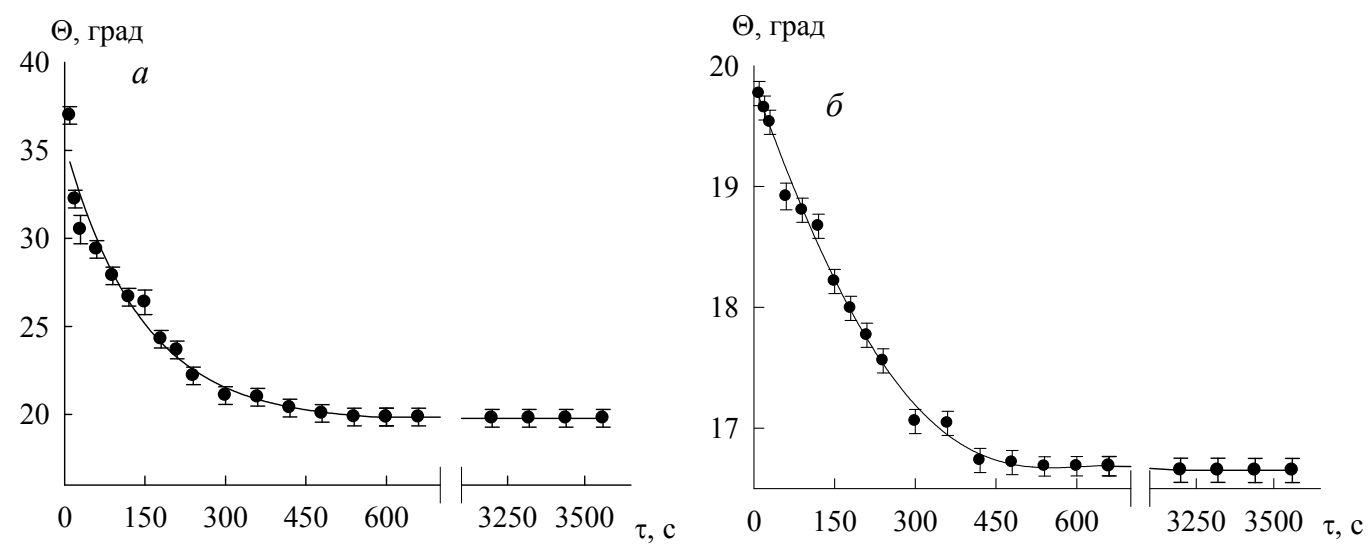

Рис. 3. Кинетика растекания расплава $\mathrm{B}_{2} \mathrm{O}_{3}+1$ мол. \% $\mathrm{Bi}_{2} \mathrm{O}_{3}$ по серебру при 923 (a) и 938 (б) K
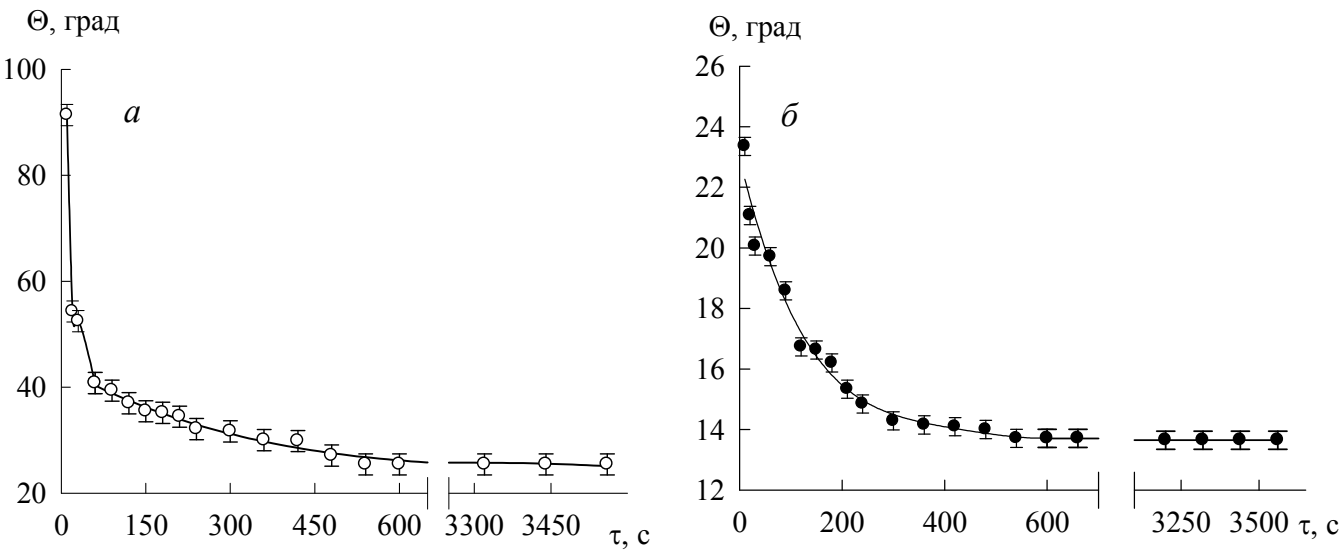

Рис. 4. Кинетика растекания расплава $\mathrm{B}_{2} \mathrm{O}_{3}+1$ мол. \% $\mathrm{Bi}_{2} \mathrm{O}_{3}$ по золоту при 923 (a) и 938 (б) К 
рассчитать работу адгезии $W_{a}$. Эти результаты показаны на рис. 5 . Видно, что с ростом температуры значения $W_{a}$ закономерно увеличиваются.

Для установления характера взаимодействия расплава $\mathrm{B}_{2} \mathrm{O}_{3}+1$ мол. $\% \mathrm{Bi}_{2} \mathrm{O}_{3}$ с подложками из серебра и золота были рассчитаны значения молярной работы адгезии $\mathrm{W}_{\mu}$ по следующему уравнению:

$$
W_{\mu}=W_{a}\left(\frac{M}{d}\right)^{2 / 3} N_{A}^{1 / 3}
$$

где $M$ и $d$ - молекулярный вес и плотность твердого тела соответственно; $N_{A}$ - число Авогадро $[21,22]$. Установлено, что $W_{\mu}$ в исследованном интервале температур практически не изменяется и для систем $\left(\mathrm{B}_{2} \mathrm{O}_{3}+1\right.$ мол. \% $\left.\mathrm{Bi}_{2} \mathrm{O}_{3}\right)-\mathrm{Ag}(\mathrm{Au})$ равна $\sim 6$ кДж/моль.

Анализ застывших капель с использованием электронного микроскопа JEOL JAM 7001F и энергодисперсионного спектрометра INCA Energy PentaFETх3 показал, что после контакта расплава $\mathrm{B}_{2} \mathrm{O}_{3}+1$ мол. \% $\mathrm{Bi}_{2} \mathrm{O}_{3}$ с твердым серебром в оксидной фазе присутствует до $\sim 1.7 \%$ $\mathrm{Ag}$. Золото после смачивания этим расплавом в последнем не обнаружено. Последнее, а также значения $W_{\mu}$ позволяют считать, что в системе $\left(\mathrm{B}_{2} \mathrm{O}_{3}+1\right.$ мол. $\left.\% \mathrm{Bi}_{2} \mathrm{O}_{3}\right)-$ Аи реализуется физическое взаимодействие фаз.

Растекание расплава $\mathrm{B}_{2} \mathrm{O}_{3}+1$ мол. \% $\mathrm{Bi}_{2} \mathrm{O}_{3}$ по поверхности $\mathrm{BeO}$ показано на рис. 6. Заметим, что значение углов смачивания в момент касания с твердой подложкой из ВеО больше таковых при смачивании $\mathrm{Ag}$ и Аu этим расплавом. Влияние температуры на смачивание и работу адгезии в системе $\left(\mathrm{B}_{2} \mathrm{O}_{3}+1\right.$ мол. \% $\left.\mathrm{Bi}_{2} \mathrm{O}_{3}\right)-\mathrm{BeO}$ отражено на рис. 7. Молярная работа в этой системе составляет $\sim 3$ кДж/моль.

Увеличение содержания $\mathrm{Bi}_{2} \mathrm{O}_{3}$ в оксидном расплаве изменяет характер взаимодействия расплав - твердое. Равновесные углы смачивания, как правило, не устанавливаются. Так, например, при 933 К за 700 с происходит практически полное растекание оксидных расплавов, содержащих 3 и 5 мол. \% $\mathrm{Bi}_{2} \mathrm{O}_{3}$, по $\mathrm{BeO}$. Полученные данные для анализируемых систем приведены в таблице.
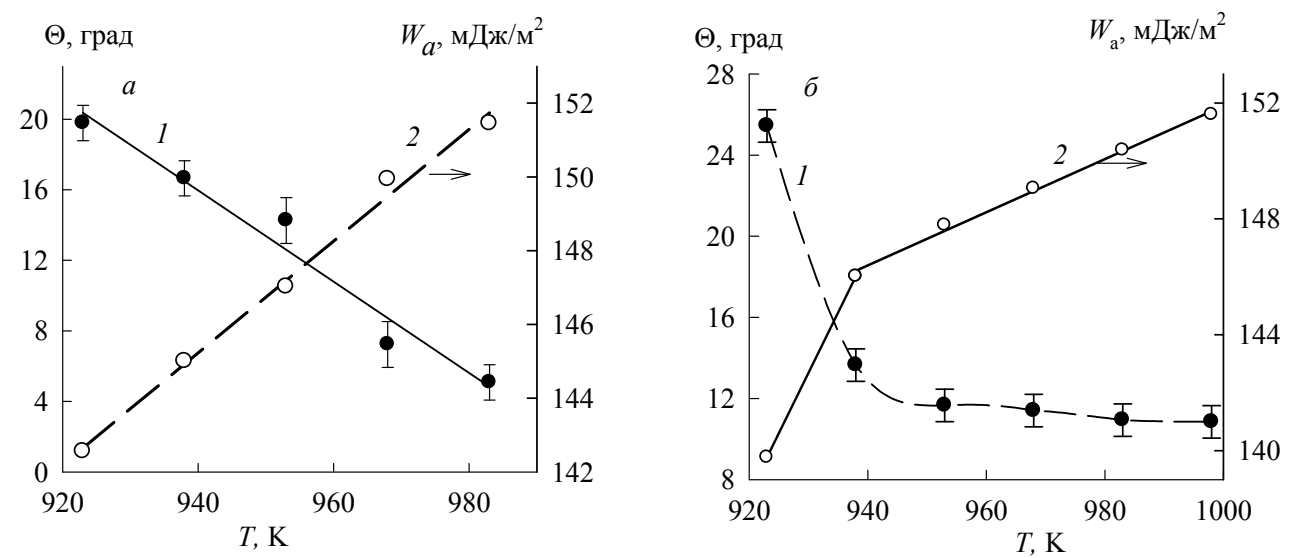

Рис. 5. Влияние температуры на смачивание (l) и работу адгезии (2) в системах $\left(\mathrm{B}_{2} \mathrm{O}_{3}+1\right.$ мол.\% $\left.\mathrm{Bi}_{2} \mathrm{O}_{3}\right)$ ж $-\mathrm{Ag}_{\text {тв }}(a)$ и $\left(\mathrm{B}_{2} \mathrm{O}_{3}+1 \text { мол.\% } \% \mathrm{Bi}_{2} \mathrm{O}_{3}\right)_{\text {ж }}-\mathrm{Au}_{\text {тв }}(\sigma)$ 
Такое быстрое растекание последних расплавов по исследованным подложкам может быть связано с уменьшением вязкости расплавов $\mathrm{B}_{2} \mathrm{O}_{3}-\mathrm{Bi}_{2} \mathrm{O}_{3}$ с ростом концентрации второго компонента [23].
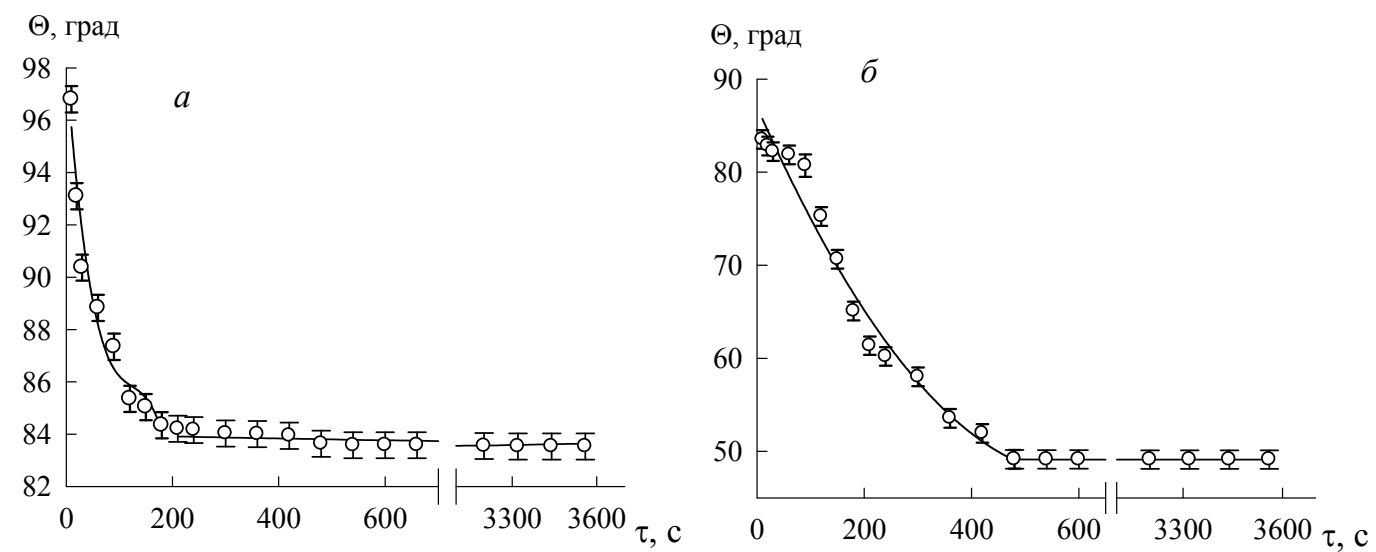

Рис. 6. Растекание расплава $\mathrm{B}_{2} \mathrm{O}_{3}+1$ мол. \% $\mathrm{Bi}_{2} \mathrm{O}_{3}$ подложке из $\mathrm{BeO}$ при 923 (a) и 938 (б) K

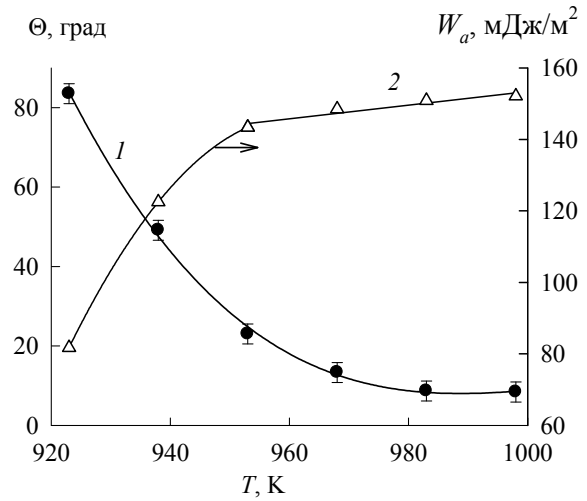

Рис. 7. Влияние температуры на смачивание и работу адгезии в системе $\left(\mathrm{B}_{2} \mathrm{O}_{3}+1\right.$ мол. $\left.\% \mathrm{Bi}_{2} \mathrm{O}_{3}\right)-\mathrm{BeO}$

Таблица. Растекание расплавов $\mathrm{B}_{2} \mathrm{O}_{3}+3(5)$ мол. \% $\mathrm{Bi}_{2} \mathrm{O}_{3}$ по $\mathrm{Ag}$, $\mathrm{Au}$ и $\mathrm{BeO}$

\begin{tabular}{|c|c|c|c|c|c|c|}
\hline \multirow{2}{*}{ Подложка } & \multicolumn{3}{|c|}{$\mathrm{B}_{2} \mathrm{O}_{3}+3$ мол. $\% \mathrm{Bi}_{2} \mathrm{O}_{3}$} & \multicolumn{3}{|c|}{$\mathrm{B}_{2} \mathrm{O}_{3}+5$ мол. $\% \mathrm{Bi}_{2} \mathrm{O}_{3}$} \\
\hline & $T, \mathrm{~K}$ & $\Theta_{\text {нач }}$, град & $\Theta_{\text {кон }}$, град & $\mathrm{T}, \mathrm{K}$ & $\Theta_{\text {нач}}$, град & $\Theta_{\text {кон }}$, град \\
\hline $\mathrm{Ag}$ & $\begin{array}{l}933 \\
948 \\
963 \\
978\end{array}$ & $\begin{array}{l}48 \\
12 \\
10 \\
10\end{array}$ & $\begin{array}{l}16 \\
10 \\
10 \\
10\end{array}$ & $\begin{array}{l}948 \\
963 \\
978\end{array}$ & $\begin{array}{l}44 \\
18 \\
16\end{array}$ & $\begin{array}{c}18 \\
16 \\
5\end{array}$ \\
\hline $\mathrm{Au}$ & $\begin{array}{r}933 \\
948 \\
963 \\
\end{array}$ & $\begin{array}{l}77 \\
18 \\
12 \\
\end{array}$ & $\begin{array}{c}18 \\
12 \\
9 \\
\end{array}$ & $\begin{array}{l}948 \\
963\end{array}$ & $\begin{array}{c}48 \\
8\end{array}$ & $\begin{array}{l}8 \\
4\end{array}$ \\
\hline $\mathrm{BeO}$ & 933 & 41 & 6 & 948 & 51 & 6 \\
\hline
\end{tabular}




\section{Список литературы}

1. Денисов В.М., Белоусова Н.В., Денисова Л.Т. Бораты висмута // Журнал СФУ. Химия. 2013. T. 6. № 2. C. 132-150. [Denisov V.M., Belousova N.V., Denisova L.T. The bismuth borates // Journal of Siberian Federal University. Chemistry. 2013. V.6. № 2. P. 132-150 (in Russ.)].

2. Каргин Ю.Ф., Жереб В.П., Егорышева А.В. Фазовая диаграмма метастабильных соединений системы $\mathrm{Bi}_{2} \mathrm{O}_{3}-\mathrm{B}_{2} \mathrm{O}_{3} / /$ Журн. неорган. химии. 2002. T. 47. № 8. C. 1362-1364. [Kargin Yu.F., Zhereb V.P., Egorysheva A.V. Metastable Phase Diagram for the $\mathrm{Bi}_{2} \mathrm{O}_{3}-\mathrm{B}_{2} \mathrm{O}_{3}$ system // Russ. J. Inorg. Chem. 2002. V. 47. № 8, p. 1362-1364. (in Russ.)].

3. Егорышева А.В., Бурков В.И., Каргин Ю.Ф., Плотниченко В.Г., Колташев В.В. Колебательные спектры кристаллов боратов висмута // Кристаллография. 2005. Т. 50. № 1. С. 135-144. [Egorysheva A.V. Burkov V.I., Kargin Yu.F., Plotnichenko V.G., Koltashev V.V. Vibrational Spectra of bismuth Borate crystals // Crystallography Reports. 2005. V. 50. № 1. P. 127-136].

4. Каргин Ю.Ф., Егорышева А.В. Синтез и особенности строения $\mathrm{Bi}_{24} \mathrm{~B}_{2} \mathrm{O}_{39}$ со структурой силленита // Неорган. материалы. 1998. Т. 34. № 7. С. 859-863. [Kargin Yu.F., Egorysheva A.V. Synthesis and structure of $\mathrm{Bi}_{24} \mathrm{~B}_{2} \mathrm{O}_{39}$ sillenita structure // Neorgan. Materiali. 1998. V. 34. № 7. P. 859863. (In Russ.)].

5. Егорышева А.В., Канищева А.С., Каргин Ю.Ф., Горбунова М.Е., Михайлов Ю.Н. Синтез и кристаллическая структура бората висмута $\mathrm{Bi}_{2} \mathrm{~B}_{8} \mathrm{O}_{15} / /$ Журн. неорган. химии. 2002. Т. 47. № 12. C. 1961-1965. [Egorysheva A.V., Kanisheva A.S., Kargin Yu.F., Gorbunova M.E. Mihailov Yu.N. Synthesis and crystal structure of bismuth borate $\mathrm{Bi}_{2} \mathrm{~B}_{8} \mathrm{O}_{15} / /$ Russian Journal of Inorganic Chemistry. V.47. № 12. P. 1804-1808].

6. Егорышева А.В., Бурков В.И., Горелик В.С., Каргин Ю.Ф., Колташов В.В., Плотниченко В.Г. Комбинационное рассеяние света в монокристалле $\mathrm{Bi}_{3} \mathrm{~B}_{5} \mathrm{O}_{12} / /$ ФТТ. 2001. Т. 43. № 9. С. 15901593. [Egorysheva A.V., Burkov V.I., Gorelik V.S., Kargin Yu.F., Koltashev V.V., Plotnichenko V.G. Raman scattering in monocrystal $\mathrm{Bi}_{3} \mathrm{~B}_{5} \mathrm{O}_{12}$.Physics of the Solid State. 2001. V. 43. № 6. P. 1655-1658].

7. Becker P. Thermal and optical properties of glasses of the system $\mathrm{Bi}_{2} \mathrm{O}_{3}-\mathrm{B}_{2} \mathrm{O}_{3} / /$ Cryst. Res. Technol. 2003. V. 38. № 1. P. 74-82.

8. Teng B., Wang J., Wang Z., Hu X., Jiang H., Liu H., Cheng X., Dong S., Liu Y., Shao Z. Crystal growth, thermal and optical performance of $\mathrm{BiB}_{3} \mathrm{O}_{6} / /$ J. Cryst. Growth. 2001. V. 233. № 1-2. P. 282-286.

9. Teng B., Wang J., Wang Z., Jiang H., Hu X., Song R., Liu H., Wie J., Shao Z. Growth and investigation of a new nonlinear optical crystal: bismuth borate $\mathrm{BiB}_{3} \mathrm{O}_{6} / /$ J. Cryst. Growth. 2001. V. 224. № 3-4. P. 280-283.

10. Hellwig H., Liebertz J., Bohaty L. Linear optical properties of the monoclinic bismuth borate $\mathrm{BiB}_{3} \mathrm{O}_{6} / /$ J. Appl. Phys. 2000. V. 88. № 1. P. 240-244.

11. Филатов С.К., Шепелев Ю.Ф., Александрова Ю.В., Бубнова Р.С. Исследование структуры оксобората висмута $\mathrm{Bi}_{4} \mathrm{~B}_{2} \mathrm{O}_{9}$ при температурах 20,200 и $450{ }^{\circ} \mathrm{C} / /$ Журн. неорган. химии. 2007. T. 52. № 1. C. 26-33. [Filatov S.K., Shepelev Yu.F., Aleksandrova Yu.V., Bubnova R.S. Structure of bismuth oxoborate $\mathrm{Bi}_{4} \mathrm{~B}_{2} \mathrm{O}_{9}$ at 20,200 , and $450^{\circ} \mathrm{C} / /$ Russian Journal of Inorganic Chemistry. 2007. V. 52. № 1. P. 21-28].

12. Денисов В.М., Белоусова Н.В., Моисеев Г.К., Бахвалов С.Г., Истомин С.А., Пастухов Э.А. Висмутсодержащие материалы: строение и физико-химические свойства. Екатеринбург: УpO PAH, 2000. 526 c. [Denisov, V.M., Belousova, N.V., Moiseev, G.K., et al. Vismutsoderzhashchie 
materialy: stroenie i fiziko-khimicheskie svoistva (Structure and Physicochemical Properties of Bismuth Containing Materials), Yekaterinburg: Ural. Otd. Ross. Akad. Nauk. 2000. 526 p. (In Russ.)].

13. Lezal D., Pedlikova J., Kostrka P., Bludska P., Poulain M., Zavadil J. Heave metal oxide glasses I preparation and physical properties // J. Non-Cryst. Solids. 2001. V. 294. P. 288-295.

14. Sanz O., Haro-Poniatowski E., Conzalo J., Navarro J.M.F. Influence of the melting conditions of heavy metal glasses containing bismuth oxide on their optical absorption // J. Non-Cryst. Solids. 2006. V. 352. P. 761-768.

15. Денисов В.М., Денисова Л.Т., Кучумова О.В., Истомин С.А., Чумилина Л.Г. Контактное взаимодействие расплавов системы $\mathrm{Bi}_{2} \mathrm{O}_{3}-\mathrm{B}_{2} \mathrm{O}_{3}$ с серебром // Расплавы. 2013. № 2. С. 42-47. [Denisov V.M., Denisova L.T., Kuchumova O.V., Istomin S.A., Chumilina L.G. Contact interaction system $\mathrm{Bi}_{2} \mathrm{O}_{3}-\mathrm{B}_{2} \mathrm{O}_{3}$ melts with silver // Rasplavy. 2013 . № 2. P. 42-47. (in Russ.)].

16. Денисов В.М., Денисова Л.Т., Кучумова О.В., Чумилина Л.Г. Смачивание золота расплавами системы $\mathrm{Bi}_{2} \mathrm{O}_{3}-\mathrm{B}_{2} \mathrm{O}_{3} / /$ Неорган. материалы. 2014. T. 50. № 2. C. 228-232. [Denisov V.M., Denisova L. T., Kuchumova O.V., Chumilina L.G. Wetting of gold by $\mathrm{Bi}_{2} \mathrm{O}_{3}-\mathrm{B}_{2} \mathrm{O}_{3}$ melts // Inorganic Materials. 2014. V. 50. № 2, P. 209-213].

17. Денисова Л.Т., Белоусова Н.В., Денисов В.М., Кучумова О.В. Взаимодействие платины с расплавами боратов висмута // Журнал СФУ. Химия. 2014. Т. 7. № 2. С. 221-225. [Denisova L.T., Belousova N.V., Denisov V.M., Kuchumova O.V. Interaction of Platinum with the Bismuth Borate Melts // Journal of Siberian Federal University. Chemistry. 2014. V. 7. № 2. P. 221-225. (in Russ.)].

18. Денисов В.М., Подкопаев О.И., Кучумова О.А., Денисова Л.Т., Истомин С.А., Корчемкина Н.В. Контактное взаимодействие иридия с расплавами $\mathrm{Bi}_{2} \mathrm{O}_{3}-\mathrm{B}_{2} \mathrm{O}_{3} / /$ Расплавы. 2013. № 4. C. 3-8. [Denisov V.M., PodkopaevO.I, Kuchumova O.V., Denisova L.T. et sl. Contact interaction of $\mathrm{PbO}-\mathrm{GeO}_{2}$ melts with silver // Rasplavy. 2013 . № 1. P. 3-8. (in Russ.)].

19. Сумм Б.Д., Горюнов Ю.В. Физико-химические основы смачивания и растекания. М.: Химия, 1976. 232 с. [Summ, B.D. and Goryunov, Yu.V., Fiziko_khimicheskie osnovy smachivaniya i rastekaniya (Physicochemical Principles of Wetting and Spreading), Moscow: Khimiya, 1976. 232 p. (in Russ.)].

20. Fujino S., Hwang C., Morinaga K. Surface tension of $\mathrm{PbO}-\mathrm{B}_{2} \mathrm{O}_{3}$ and $\mathrm{Bi}_{2} \mathrm{O}_{3}-\mathrm{B}_{2} \mathrm{O}_{3}$ glass melts // J. Mater. Sci. 2005. V. 40. P. 2207-2212.

21. Найдич Ю.В., Колесниченко Г.А. Взаимодействие металлических расплавов с поверхностью алмаза и графита. Киев: Наукова думка, 1967. 89 с. [Naidich, Yu.V. and Kolesnichenko, G.A., Vzaimodeistvie metallicheskikh rasplavov s poverkhnost'yu almaza i grafita (Interaction of Metallic Melts with the Surface of Diamond and Graphite). Kiev: Naukova Dumka, 1967. 89 p. (in Russ.)].

22. Казакевич Э.А., Думенко Л.П., Жемчужина Е.А. Исследование физико-химического взаимодействия двойных сплавов на основе висмута на границе с твердыми растворами системы Bi-Sb-Se-Te, медью и никелем // Контактные свойства расплавов. Киев: Наукова думка. 1982. C. 46-49. [Kazakevich E.A., Dumenko L.P., Zhemchuzhina E.A. Interfacial physicochemical interaction of bismuth based binary melts with $\mathrm{Bi}-\mathrm{Sb}-\mathrm{Se}-\mathrm{Te}$ solid solutions, copper, and nickel, in Kontaktnye svoistva rasplavov (Contact Properties of Melts), Kiev: Naukova Dumka, 1982, p. 46 (in Russ.)]. 
23. Денисов В.М., Истомин С.А., Денисова Л.Т., Рябов В.В., Чумилина Л.Г., Кучумова О.В. Вязкость расплавов системы $\mathrm{Bi}_{2} \mathrm{O}_{3}-\mathrm{B}_{2} \mathrm{O}_{3} / /$ Расплавы. 2013. № 1. C. 43-49. [Denisov V.M., Istomin S.A., Denisova L. T., Ryabov V.V., Chumilina L.G., Kuchumova O.V. Viscosity of system $\mathrm{Bi}_{2} \mathrm{O}_{3}-\mathrm{B}_{2} \mathrm{O}_{3}$ melts // Rasplavy. 2013 . № 1. P. 43-49. (in Russ.)]. 